\title{
NOTE ON THE INTERPRETATION OF CLEARANCE METHODS IN THE DISEASED KIDNEY
}

\author{
BY HOMER W. SMITH \\ (From the Department of Physiology, New York University College of Medicine, New York City)
}

(Received for publication June 16, 1941)

In interpreting the results obtained by clearance methods in the diseased kidney, the physiological limitations of these methods must be kept clearly in mind. Since there has been no opportunity to discuss these limitations generally, it has seemed desirable to emphasize certain more important points in this note.

The four methods to be considered here are the inulin clearance $\left(C_{I N}\right)$, the plasma diodrast clearance $\left(C_{D}\right)$, the maximal rate of tubular excretion of diodrast $\left(T m_{D}\right)$ and the maximal rate of tubular reabsorption of glucose $\left(T m_{G}\right)$, all four methods being based on overall measurements made on the two kidneys by the collection of bladder urine $(4,10,12)$.

\section{DEFINITIONS}

It will aid in the following discussion if certain terms are given restricted definitions.

A normal active nephron designates a patent glomerulus with its tubule- both glomerulus and tubule functioning, by virtue of an adequate supply of blood delivered at an adequate pressure, in the formation of glomerular filtrate and in tubular excretion and reabsorption.

At least by definition, the glomeruli and tubules of normal nephrons may become partly or wholly inactive due to ischemia without losing their potentiality for immediate return of function on the restoration of an adequate blood supply.

An aglomerular tubule is one in which excretory function and urine formation persist after destruction of the adjoined glomerulus. (There is as yet no functional evidence of the existence of aglomerular tubules in the normal or diseased human kidney; it remains to be demonstrated that the mammalian nephron, which normally reabsorbs water, can acquire the capacity to excrete it, and the excretion of water must be presupposed if the term "aglomerular nephron" is to have functional significance.)

An impotent nephron is conceived as one in which the tubule remains anatomically intact and connected with an active glomerulus and a patent collecting duct despite the fact that it has lost its excretory activity, as tested by diodrast. Such a tubule would act as a more or less passive conduit to drain glomerular filtrate into the urine. Whether such impotent nephrons simultaneously lose all other tubular properties, such as the capacity to reabsorb glucose, chloride, water, etc., is not to be answered $a$ priori but only by investigation; but since by definition they are unable to excrete diodrast they do not contribute to $C_{D}$ or $T m_{D}$.

All renal parenchyma which normally lacks excretory function, or which has lost its excretory function, will be designated as inert tissue. This would include capsular and connective tissue, impotent nephrons as defined above, injured nephrons which permit the back-diffusion of inulin and other constituents of the tubular urine, nephrons which are obstructed by casts or disconnected from collecting ducts so that urine formation is impossible, and fibrotic glomeruli and tubular fragments generally.

\section{Total renal function and function in individual nephrons}

Recognizing that there are two million-odd nephrons in the two kidneys, it is self-evident that no overall method of examination can directly reveal what is occurring in individual nephrons. The total clearance method cannot reveal whether impairment in any of the above functions is the result of the partial reduction of function in all nephrons or the complete reduction of function in a few. Conversely, constancy of these functions does not imply constancy in all contributing nephrons, since function may be increased in some at a time when it is decreased in others.

The above considerations are most obviously applicable to $C_{I N}$ and $C_{D}$, which in their physiological nature must be presumed to be highly labile in any one nephron. But to a lesser degree these considerations also apply to $T m_{D}$ and $T m_{G}$; although these measurements are based on saturation methods and presumably represent the maximal attainable activity in all available nephrons, nevertheless the availability of a particular nephron depends, in the case of $T m_{D}$, on perfusion by blood, and in the case of $T m_{G}$, on glomerular filtration; hence alternation of activity and partial, as compared with complete, cessation of activity in individual nephrons are theoretically possible. There is also the possibility that the functional contribution of indi- 
vidual nephrons may be related to "trophic" or other influences. For example, White, Heinbecker and Rolf (16) have recently shown that $T m_{D}$ is decreased in hypophysectomized dogs; hypertrophy of the kidneys occurs in animals receiving large doses of androgens and estrogens $(5,6,7,8,9)$, and the hypertrophy of the kidney induced by a high protein diet is well known. While it has not yet been shown that either $T m_{D}$ or $T m_{G}$ is increased in these hypertrophic kidneys, a functional change is to be anticipated.

\section{Filtration of water and the inulin clearance}

The term "glomerular filtration" may be used primarily to designate the passage of water across the glomerular membranes. Since a variable quantity of water is reabsorbed by the tubule, it is impossible, either in a single nephron or in the total kidneys, to deduce from the urine flow how much water is filtered from the blood. The rate of filtration of water can only be deduced in either case by means of an appropriate standard of reference, namely, a completely filtrable solute which is itself neither reabsorbed nor excreted by the tubule; and in turn the selection of this standard of reference can be made only by a comparison of clearances (i.e., rates of excretion relative to plasma concentration) of various substances under various physiological conditions. The use of inulin as the standard of reference for the measurement of the rate of filtration of plasma water rests upon good experimental evidence, so far as the normal human kidney is concerned (13). ${ }^{1}$

In the diseased kidney, however, an increase in permeability of the tubule may permit the escape of water from the tubular urine without permitting the escape of inulin; and, conversely, a decrease in permeability of the glomerular membranes may retard the filtration of inulin without proportionally retarding the filtration of water; ${ }^{2}$ in either case, the differential movement

${ }^{1} C_{I N}$ may be calculated as cc. of plasma water instead of cc. of plasma, but this is superfluous where other analyses and calculations refer to cc. of plasma, and where it is convenient to speak of volumes of plasma filtered.

$2 A$ reduction in the filtration of water resulting from decreased permeability of the glomerular membranes requires that in the glomerular capillaries equilibrium between the hydrostatic pressure and the opposed forces of water cannot be detected by changes in $C_{I N}$, although, if the alternative possibility can be ruled out, it may conceivably be deduced by the comparison of $C_{I N}$ with the clearance of some smaller molecule. ${ }^{3}$

Lastly, it is conceivable that filtration may continue in a glomerulus after the attached tubule has become separated from its collecting duct, or that the tubule may become so permeable that all the constituents in the glomerular filtrate, including inulin, escape into the interstitial fluid rather than the urine. $C_{I N}$ represents only such inulin as is passed into the bladder and will reveal nothing of these circumstances. Whatever significance the complete local reabsorption of glomerular filtrate may have in renal pathology, it remains beyond the possibility of examination so long as only the total urine is available for analysis.

\section{Renal blood flow and diodrast clearance}

The diodrast clearance may be defined as the virtual volume of plasma completely cleared of diodrast by the renal parenchyma per unit of time. On the assumption that the diodrast is completely removed from all plasma presented to active excretory tissue, it may be identified as the actual plasma flow to this tissue. This identification, however, does not include plasma (or blood) which perfuses inert tissue, and consequently $C_{D}$ bears no certain relation to the total renal blood flow. But inasmuch as $C_{D}$ approaches in magnitude the total renal blood flow, it affords in effect a method of following the latter, but subject only to the necessary qualifications with respect to the completeness of extraction from the total renal blood.

(oncotic plus capsular pressure) is not reached, or is not approached as closely as in the normal glomerulus (11).

The parallel behavior of urea and inulin in all stages of diffuse glomerular nephritis indicates that the reduced excretion of both substances is primarily attributable to the obliteration of the filtering bed rather than increased back-diffusion of urea (1).

Similarly the identity of the inulin and hexitol clearances in women with pre-eclampsia (13) argues against a significant decrease in glomerular permeability in a disease where thickening of the glomerular membranes is frequently observed. There is here no reason to suspect that a precisely compensating increase in tubular permeability has obscured a decrease in glomerular permeability, since tubular function is apparently not disturbed (14). 
In this connection we may first note the consequences of the appearance in the renal pattern of impotent nephrons. The efferent blood from the glomerulus attached to the impotent tubule -blood which once was cleared by this tubule will be available for clearance by such normal tubules as are located within the maximal sphere of diffusion of diodrast, etc., or circulation of the interstitial fluid.

With regard to diffusion, a concentration gradient will be established between the capillary of the impotent tubule and such normal tubules as are excreting diodrast; at a constant plasma concentration of diodrast, the time required for molecules to move the length of this gradient may be neglected, and the radius of diffusion may be conceived to be limited only by some actual interruption of the diffusion free-way. Conceivably, the diodrast cleared by a particular tubule may diffuse out of a remote capillary.

With regard to the circulation of interstitial fluid, it will be noted that out of $135 \mathrm{cc}$. of glomerular filtrate formed each minute, the greater fraction is reabsorbed by the tubules and must pass across the interstitial space to the capillary before it re-enters the blood. It cannot be imagined that this movement of water occurs along the shortest possible point-to-point route; on the contrary, there must be a considerable streaming between or along the tubules which is aided by the arterial pulse. This streaming will not only accelerate the movement of diodrast from capillary to excretory tubule but it may also increase the radius of clearance to a much larger area than diffusion alone would permit. Although diffusion and the circulation of renal interstitial fluid must play an important rôle in normal renal function, ${ }^{4}$ their significance is ex-

- The fact that an average plasma extraction ratio of 0.74 (15) or 0.85 (2) is observed in the explanted dog kidney is in itself unexpected, since some postglomerular blood must pass rapidly to medullary tissue which is supposed to be reabsorptive rather than excretory; physical diffusion and circulation of interstitial fluid probably obviate the local distribution of blood and aid in the maintenance of this high extraction ratio. Any circumstance which would restrict the movement of interstitial fluid (increased intrarenal pressure, perinephritis, etc.) would be equivalent in effect to a reduction in actual blood flow to such areas in the kidney as might be dependent for their perfusion on the circulation of interstitial fluid rather than on a direct blood supply. The meager facts perimentally more evident in the diseased kidney.

The increased volume of blood which is made available for clearance by the formation of impotent nephrons will appear in clearance tests as an apparent hyperemia of the residual functional tissue (increase in $C_{D}$ relative to $T m_{D}$ ); but unlike the hyperemia resulting from either dilatation of the renal arterioles or increased perfusion pressure, this apparent hyperemia may not afford the normal tubules a proportionately increased supply of oxygen, etc., and it seems advisable to distinguish it from true hyperemia (vascular dilatation) by qualifying it as a vicarious hyperemia.

It is conceivable that loss of excretory activity may occur in large areas of a kidney, in single tubules, or in alternate cells of a tubule; in any of these instances, the extraction ratio of diodrast in the blood which once was cleared by the now defunct tissue (unless it is anatomically available for vicarious clearance by residual functional units) will decrease from its high normal value (which we nominally take as 1.0 ) and ultimately fall to zero. Thus, in considering the diseased kidney as a whole, the overall extraction ratio may be expected to have any value between 1.0 and 0.0 , and $C_{D}$ will have a very uncertain relation to the total renal blood flow. ${ }^{5}$ This circumstance does not, however, impair the usefulness of the clearance method; on the contrary, it is under these conditions that it acquires a unique physiological significance.

It will perhaps aid the reader to visualize the following argument if, as an extreme example, an inert cannula is imagined to be inserted between the renal artery and the renal vein of a normal kidney so that some large fraction of the renal arterial blood passes directly to the renal vein by way of this cannula. Since the clearance method depends upon the presence of living excretory tissue to remove diodrast (or some other suitable substance) from the blood and excrete it in the urine, this method can never discover how much blood passes from renal ar-

which are known about this process indicate that the major movement of fluid is from the medulla towards the periphery of the kidney (3).

- This circumstance was recognized in our original description of the diodrast clearance method (12) and was the basis of the definition of this clearance as the effective renal blood, i.e., the virtual volume of blood which is completely cleared of diodrast. 
tery to renal vein through the cannula. Nor will the cannula begin to excrete diodrast when the plasma concentration is raised; that is, it will not only fail to contribute to $C_{D}$ such diodrast as is carried by the blood passing through it at low concentrations, but it will also fail to contribute diodrast to $T m_{D}$ when this is measured at high plasma concentrations. The same consideration applies to blood exclusively perfusing inert tissue; ${ }^{6}$ if particular diodrast molecules are not brought into effective juxtaposition with functional excretory tissue for clearance at a low plasma concentration, in general ${ }^{7}$ they will not be made available for clearance simply in consequence of increasing the plasma concentration. And any tissue incapable of excreting diodrast

\footnotetext{
"The term "exclusively perfusing" excludes diffusion through and circulation of the interstitial fluid, while the term "inert tissue" excludes normal tubular tissue which is inactive simply in consequence of ischemia or because it is presented only with blood which has previously been cleared of diodrast.

I It is conceivable that a decrease in permeability of the capillaries, interstitial tissue or tubule cell, or some change in the tubular excretory mechanism itself, could retard the movement of diodrast from blood to urine; since the blood is available for clearance in the peritubular capillary for only a brief period, this retardation would lower the percentage of the diodrast removed during its passage down this capillary. But whether the retarding factor is conceived as a positive barrier (e.g., impermeable connective tissue) or a negative fault (e.g., failure of the tubule cell to handle all molecules available to it), it would be expected that the retardation would operate on any and all molecules of diodrast with statistical indifference, with the result that the clearance probabilities for any particular molecule would not be increased by increasing the number of molecules.

Exceptions to the above statement are conceivable: one might imagine that at a low concentration so large a fraction of diodrast was absorbed on the plasma protein that escape from the capillary by diffusion was greatly retarded and the extraction ratio correspondingly reduced; if now at some higher concentration the plasma proteins became saturated, the diffusion of diodrast from the capillary, and consequently the extraction ratio, would be increased. Since protein binding is a function of diodrast concentration, this particular situation, chosen for illustration only, is not to be expected in practice. Whether or not as a result of disease a change in the kinetics of the tubular excretory process could have this consequence is undetermined, but it would seem that the problem can be examined by the progressive elevation of the plasma diodrast level. Such titrations as have been made by us to date have supplied no evidence of such a change.
}

at low plasma levels will not acquire excretory capacity by virtue solely of an increased concentration of diodrast. We may generalize from the above by saying that where the plasma concentration is the only changing factor, inert tissue is excluded from both $C_{D}$ and $T m_{D}$; hence in the measurement of $C_{D}$ and $T m_{D}$ the same vascular and interstitial channels are involved, and in turn $C_{D}$ and $T m_{D}$ refer to the same nephrons or other units of excretory activity. Whether $T m_{D}$ is conceived in terms of entire nephrons, individual cells or hypothetical excretory units of minimal dimensions, is immaterial: the ratio $C_{D} / T m_{D}$ expresses the virtual quantity of plasma completely cleared of diodrast per unit quantity of the excretory tissue which is effecting this clearance. $C_{D}$ here has the same definition and the same significance as in the normal kidney in which, as emphasized above, there is already some inert tissue and some uncleared blood; if in disease some of the blood presented to a particular nephron or a particular tubule cell escapes uncleared, the significance of the ratio remains unchanged.

Thus a reduction in the overall extraction ratio of diodrast in the diseased kidney does not seriously impair the usefulness of the clearance method. On the contrary, this method is the only one capable of determining the volume of blood cleared by such functional excretory units as are inextricably mixed with scar tissue, tubular detritus, connective tissue, etc., a datum upon which no information could be gained by the measurement of the total renal blood flow. When the diodrast clearance is referred to the total quantity of available functional tissue, i.e., by utilization of the ratio $C_{D} / T m_{D}$, a datum is obtained which in most instances will be qualitatively and quantitatively comparable with observations made on the normal kidney. Even in normal subjects, $C_{D}$ should be related to $T m_{D}$ in order to take into account the varying quantities of excretory tissue which may be expected to occur in different individuals.

\section{SUMMARY}

The interpretation of clearance methods (the inulin and diodrast clearance, and diodrast $T m$ ) in the diseased kidney is discussed. 


\section{BIBLIOGRAPHY}

1. Chasis, H., and Smith, H. W., The excretion of urea in normal man and in subjects with glomerulonephritis. J. Clin. Invest, 1938, 17, 347

2. Corcoran, A. C., Page, I. H., and Smith, H. W., Renal excretion of diodrast in the dog. Am. J. Physiol. (Proc.), 1940, 129, 339.

3. Fuchs, F., and Popper, H., Blut und Saftströmung in der Niere. (Zur klinischen Bedeutung des Niereninterstitiums.) Ergeb. inn. Med., 1938, 54, 1.

4. Goldring, W., Chasis, H., Ranges, H. A., and Smith, H. W., Relations of effective renal blood flow and glomerular filtration to tubular excretory mass in normal man. J. Clin. Invest., 1940, 19, 739.

5. Korenchevsky, V., and Ross, M. A., Kidneys and sex hormones. Brit. Med. J., 1940, 1, 645.

6. Ludden, J. B., Krueger, E., and Wright, I. S., Effect of testosterone propionate, estradiol benzoate and desoxycorticosterone acetate on the kidneys of adult rats. Endocrinology, 1941, 28, 619.

7. MacKay, E. M., Degree of compensatory renal hypertrophy following unilateral nephrectomy. III. Influence of testosterone propionate. Proc. Soc. Exper. Biol. and Med., 1940, 45, 216.

8. Pfeiffer, C. A., Emmel, V. M., and Gardner, W. U., Renal hypertrophy in mice receiving estrogens and androgens. Yale J. Biol. and Med., 1940, 12, 493.
9. Selye, H., The effect of testosterone on the kidney. J. Urol., 1939, 42, 637.

10. Smith, H. W., The physiology of the renal circulation. Harvey Lect., 1939-40, Series 35, 166.

11. Smith, H. W., Chasis, H., Goldring, W., and Ranges, H. A., Glomerular dynamics in the normal human kidney. J. Clin. Invest., 1940, 19, 751.

12. Smith, H. W., Goldring, W., and Chasis, H., The measurement of the tubular excretory mass, effective blood flow and filtration rate in the normal human kidney. J. Clin. Invest., 1938, 17, 263.

13. Smith, W. W., Finkelstein, N., and Smith, H. W., Renal excretion of hexitols (sorbitol, mannitol, and dulcitol) and their derivatives (sorbitan, isomannide, and sorbide) and of endogenous creatinine-like chromogen in dog and man. J. Biol. Chem., 1940, 135, 231.

14. Wellen, I., Welsh, C. A., and Taylor, H. C., Jr., The filtration rate, effective renal blood flow, tubular excretory mass and phenol red clearance in specific "toxemia" of pregnancy. (In press.)

15. White, H. L., Observations on the behavior of diodrast in the dog. Am. J. Physiol., 1940, 130, 454.

16. White, H. L., Heinbecker, P., and Rolf, D., Effects of hypophysectomy on some renal functions. Proc. Soc. Exper. Biol. and Med., 1941, 46, 44. 